\title{
NEUROTIC EXCORIATION AND THE RELATIONSHIP WITH PSYCHOLOGICAL ASPECTS: A SYSTEMATIC REVIEW
}

\author{
Dr. Idiberto Jose Zotarelli Filho, MSc, Ph.D ${ }^{1}$
}

${ }^{1}$ Affiliation not available

July 6, 2020

\begin{abstract}
Among psychiatric dermatoses, neurotic excoriation is characterized by the patient's confession of causing lesions on the skin itself, without presenting a basic dermatological disease. The theme has been gaining prominence since the incorporation of the diagnosis in the American Psychiatric Association Diagnostic and Statistical Manual of Mental Disorders (DSM-5, APA 2014). However, it was found that the subject has been scarcely addressed in the literature since not all cases are diagnosed and this pathology has more than one denomination (excoriation disorder, pathological palpation of the skin, neurodermatitis, dermatotillomania, and psychogenic excoriation). Therefore, the present study addressed the main clinical findings in research studies, through a systematic review, on neurotic excoriation, in addition to valuing the importance of psychological aspects in etiopathogenesis.
\end{abstract}

Keywords: Neurotic excoriation. Excoriation disorder. Itching. Skin picking. Dermatotillomania.

\section{Caroline Araújo Gonçalves ${ }^{1}$, Giedre Ingrid das Neves Pereira ${ }^{2,3}$, Idi- berto José Zotarelli Filho ${ }^{4-6}$}

1. Base Hospital of São José do Rio Preto/SP, FUNFARME, Brazil.

2. Institute of Behavioral Cognitive Psychotherapy (Instituto de Psicoterapia Cognitivo Comportamental, IPC), São José do Rio Preto/SP, Brazil

3. Unip- Universidade Paulista (University of São Paulo) of São Jose do Rio Preto/SP, Brazil.

4. Zotarelli-Filho Scientific Work, São José do Rio Preto, SP, Brazil.

5. $\quad$ Bentham Science Ambassador, São José do Rio Preto/SP, Brazil.

6. $\quad$ Faceres, Medical School, São José do Rio Preto/SP, Brazil.

\section{Introduction}

The correlation between psychiatric and dermatological disorders is highly complex, considering etiology, diagnosis, and treatment. The skin and the nervous system, of which the brain is the central organ, have the same origin during the formation of the embryo. Both are of ectodermal origin and, therefore, there is an important interaction between them [1]. 
In this scenario, the excoriation disorder (ED), also known as dermatillomania, psychogenic excoriation, or neurotic excoriation, is characterized by the recurrent choice of skin, leading to skin lesions and significant suffering or functional impairment $[1,2]$.

Although documented in the medical literature since the 19th century, ED has only recently been included as a distinct entity in conventional psychiatric nosology. In the Diagnostic and Statistical Manual of Mental Disorders, 5th Edition (DSM-5) and in the proposed International Classification of Diseases, 11th Revision (ICD-11), ED is listed as one of the obsessive-compulsive and related disorders (OCRDs), due to its overlap with conditions such as trichotillomania [3].

Epidemiological data indicated a prevalence of neurotic excoriation of 2 to $3 \%$, in relation to the general population, $2 \%$, among dermatological patients, and $9 \%$, in patients with pruritus [4]. Lesions are seen in the places most easily reached by the hands, such as the face and upper limbs [5]. It affects both sexes in different age groups with a significant predominance in women. The patient admits to causing skin lesions repeatedly and frequently, being unable to avoid the repetitive process, characterizing the compulsion [6].

Emotion finds in the skin a means of physical expression. The records of the most diverse feelings are marked there in the form of scars. The lesions of the disease mark the space of a physical and also a psychological wound, taking the person as a psychosomatic totality [7].

According to Azambuja (2009) [8], the abrasions do not result from neurosis, but from a very particular mental process that forces the person to scrape himself as a form of stress relief, whose energy is diverted to a repetitive gesture of rubbing, scratching, scratch or pluck the skin. Scratching is one of the archaic forms of the return of aggression on the body. In terms of treatment, there is a shortage of data. However, management currently has a comprehensive psychiatric examination, behavioral therapy, and medication.

Therefore, the present study addressed the main clinical findings in research studies on neurotic excoriation, in addition to valuing the importance of psychological aspects in etiopathogenesis.

\section{Methods}

\section{Data sources and search strategy}

A total of 89 articles were found involving the MeSH Terms "Neurotic excoriation", "excoriation disorder", "itching", "skin picking" and "dermatotillomania". Initially, it was held the existing exclusion title and duplications following the interest described in this work. After this process, 21 articles were included and discussed in this study (Figure 1). PUBMED, EMBASE, OVID AND COCHRANE LIBRARY databases were searched. Initially, the descriptors were determined by searching the DeCS tool and later verified and validated by the MeSH Terms System (US National Library of Medicine). The present study was elaborated according to the rules of systematic review- PRISMA (Transparent reporting of systematic reviews and meta-analyses- http://www.prisma-statement.org/). 
Figure 1. Flow Chart of the article selection process.

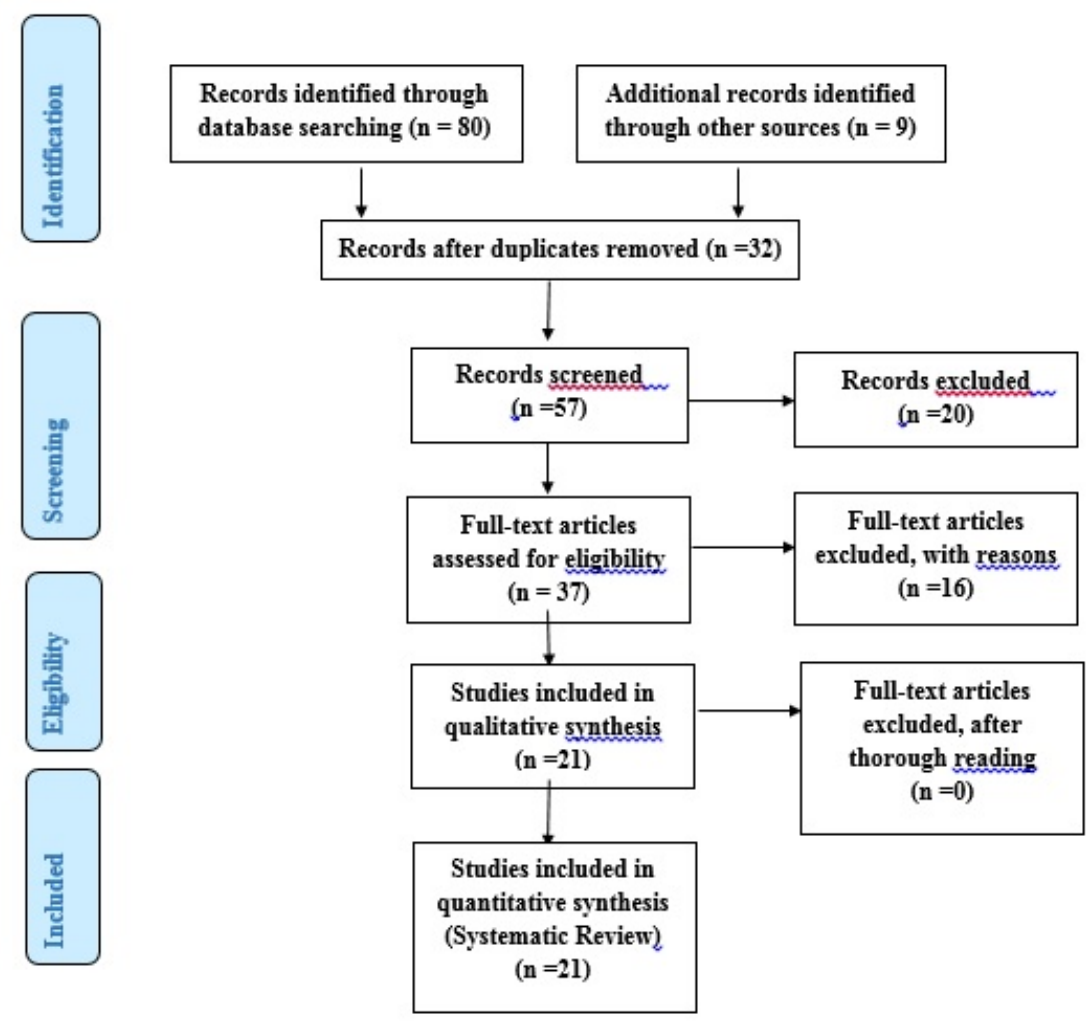

\section{Study selection and risk of bias in each study}

Two independent reviewers (1 and 2) performed research and study selection. The data extraction was performed by reviewer 1 and fully reviewed by reviewer 2. A third investigator decided some conflicting points and made the final decision to choose the articles. Only studies reported in Portuguese and English were evaluated. The Cochrane instrument was adopted to assess the quality of the included studies.

\section{Risk of bias}

Considering the Cochrane tool for risk of bias, the overall evaluation resulted in 4 studies with a high risk of bias and 2 studies with uncertain risk. Five studies had a limited number of participants. Also, the absence of the source of financing in 1 studies. Further, 2 studies did not disclose the information on the conflict of interest statement.

\section{Development and Discussion}

The association between psychiatric and dermatological disorders has been well characterized in the current literature, with estimates of up to $40 \%$ of patients with dermatology with concomitant psychiatric problems, often related to their skin condition [3].

The most common underlying psychopathological conditions are depression and anxiety, borderline personality disorder, body dysmorphic disorder, substance use disorder, eating disorders, trichotillomania, and kleptomania. Self-destructive behavior, difficulty expressing anger, and obsessive-compulsive disorder are also identified. In this sense, loss, recent grief, and obsessive-compulsive personality are factors that can be related to the diagnosis [7]. Emotional traumas suffered during child development, abandonment, family breakdown, restricted emotional ties, adulthood with difficulties in performing tasks that require emotional 
maturity, and the ability to control impulses. Family histories were notable for depressive disorders and psychoactive substance use disorders. Most patients experience increasing tension before excoriation and relief after [7].

Committed to the task of integrating the work of dermatologists and psychologists, Psychodermatology has proposed to research and treat dermatoses that present factors that are more susceptible to psychological determinants $[8,9]$. Torres emphasizes the importance of understanding the psychiatric conditions present in dermatoses, thus, the case discussion in an interdisciplinary team can prove to be an effective strategy due to the complexity of the symptoms that the patient may present $[10,11]$. Within psychogenic dermatoses are neurotic excoriations. They are characterized by compulsive self-produced lesions with the nails that the patient justifies by the uncontrollable sensation of itching, burning, or the need to remove something from the skin, such as small follicular papules, keratosis or other elements [12].

There is a vicious circle between itching, scarring, and skin damage, which again leads to an uncomfortable feeling and scratching. The chronicity of skin lesions result in the thickening of the epidermis with accentuation of the grooves and color, a reaction called lichenification [13]. Fingernails can be usual agents and abrasions can take typical forms. The lesions may be primary or be associated with a pre-existing lesion of another nature, which may occur on the face, or on any part of the body, and the pruritus may be present, but it is rarely perceived as a primary lesion. Excoriations are usually less than an inch in diameter and are covered with hematic crusts and erythematous borders. Its resolution can leave a clear scar with hyperpigmented edges. Lesions are noted in all stages, usually more frequent and concentrated in the forearms, face, neck, and shoulders. In general, patients are under stress and depressed, and the compulsive aspect refers to unconscious feelings of guilt and the need for self-punishment [13].

In this context, a clinical study evaluated the psychiatric characteristics of neurotic excoriation and investigated the effect of traumatic events in childhood on the disease [14]. Thirty-eight patients with neurotic excoriations who had not received psychiatric treatment in the past year and 40 healthy individuals with similar sociodemographic characteristics were included in the study. For clinical evaluation, the DSM-IV Structured Clinical Interview for Axis I Disorders, Beck's Depression Inventory, Beck's Anxiety Inventory, and the Short Form Childhood Trauma Questionnaire were applied to all individuals. It was observed that $78.9 \%$ of patients with neurotic excoriations were diagnosed with at least one Axis I psychiatric disorder, whose most frequent diagnoses were severe depressive disorders and anxiety disorders. The levels of anxiety and depression were significantly higher in the patient group than in healthy individuals. In relation to the Childhood Trauma Questionnaire, the emotional neglect, emotional abuse, and physical abuse subscales, and the weighted average total scores were significantly higher in the patient group $(\mathrm{p}<0.05)$. Therefore, there is a close relationship between neurotic excoriations and traumatic events in childhood, as well as the psychiatric problems that accompany them. We assume that early interventions by dermatologists and psychiatrists and, in particular, a detailed investigation of traumatic events in childhood, establishing a therapeutic collaboration, are highly important and that the use of psychotherapeutic interventions can result in better treatment results in many patients [14].

In this sense, the doctor-patient relationship is extremely important for better acceptance of the diagnosis and for greater adherence to treatment [15-17]. Currently, the therapeutic conduct of neurotic excoriation consists of an indication of antidepressants and antipsychotics. Among the non-medication therapeutic possibilities, the literature refers to behavioral psychotherapy, focal, or brief [18].

The goal of psychotherapy is to bring repressed feelings to the surface through the use of verbalized content. Treatments considered effective in case reports include a behavioral technique called "habit reversal"; which consists of self-monitoring, recording of episodes of scratches, and procedures that produce alternative responses to scratching [19].

Thus, pharmacological therapies that include selective serotonin reuptake inhibitors (SSRIs), serotoninnoradrenaline reuptake inhibitors, antipsychotics, and glutaminergic modulating agents. SSRIs and Nacetylcysteine proved to be effective. In addition, atomoxetine is a selective noradrenaline reuptake inhibitor 
used in the treatment of attention-deficit / hyperactivity disorder (ADHD). A case report presented a 9year-old girl with a comorbid diagnosis of ADHD and ED successfully treated with atomoxetine. There was a positive result in the performance of this drug, but more studies are needed on the effectiveness of atomoxetine in the treatment of ED in the presence and absence of ADHD [20]. Thus, there is a search for a clinical solution, through dermatological consultations, which, when unsuccessful, increase anxiety, making patients more frustrated, worsening existing psychological symptoms [20].

In addition, a systematic review study analyzed the evidence on skin disorder, as defined by the Arnold criteria or the Diagnostic and Statistical Manual of Mental Disorders - fifth edition (DSM-5), and examined whether the skin palpation disorder justifies the inclusion in DSM-5 as a distinct disorder [21]. Thus, a total of 20 studies were considered eligible in 1554. Most of the articles were case-control studies with small clinical samples. Only one of Blashfield's five criteria was met. There were commonly accepted diagnostic criteria and evaluation scales present in the literature. Only a small proportion of published studies on skin disorder used validated criteria. Therefore, the current literature fulfills only one of the five Blashfield criteria for the inclusion of skin palpation disorder as a specific entity in psychiatric diagnostic manuals. More empirical studies on skin palpation disorder are needed to substantiate skin palpation disorder as a disorder distinct from related disorders in the obsessive-compulsive category and related disorders [21].

\section{Conclusion}

It is concluded, therefore, the importance of early and correct diagnostic evaluation, in order to avoid further physical and psychological damage to patients. The multidisciplinary approach is necessary considering the patient as a whole, taking into account individual, physical, psychological, family, social and lifestyle characteristics. This study can contribute to a better understanding of the disease and the factors that involve it, covering prophylaxis, treatment, and management of triggering and punctuating factors of the disease.

\section{Declaration of conflicts of interest}

The authors declare nothing.

\section{References}

1. Lochner C, Roos A, Stein DJ. Excoriation (skin-picking) disorder: a systematic review of treatment options. Neuropsychiatr Dis Treat. 2017;13:1867-1872. Published 2017 Jul 14. doi:10.2147/NDT.S121138.

2. Seale L, Gaulding JV, Porto D, Prabhakar D, Kerr H. Implementation of a psychodermatology clinic at a major health system in Detroit. Int J Womens Dermatol. 2018;4(4):227-229. Published 2018 Jul 7. doi:10.1016/j.ijwd.2018.05.002.

3. Šitum M, Kolić M, Buljan M. Acta Med Croatica. 2016;70 Suppl 1:35-38.

4. Koblenzer CS, Gupta R. Neurotic excoriations and dermatitis artefacta. Semin Cutan Med Surg. 2013;32(2):95-100. doi:10.12788/j.sder.0008.

5. Basta-Juzbašić A, Bukvić Mokos Z. Skin changes in primary psychiatric disorders. Acta Dermatovenerol Croat. 2015;23(2):87-95.

6. Koo J, Lebwohl A. Psycho dermatology: the mind and skin connection. Am Fam Physician. 2001;64:1873-8. 3. Hoffmann FS, Zogbi H, Fleck P, Müller MC. A integração mente e corpo em psicodermatologia. Psicol Teor Prát. 2005;7:51-60.

7. Martelli AC. Ipele [online]. São José do Rio Preto: Dermatoses psiquiátricas. [update 11 outubro 2006; citado 13 maio 2008]. Disponível em: http:// www.ipele.com.br/livro/capítulo

8. Azambuja,R D. Dermatologia integrativa: a pele em novo contexto. Anais brasileiros de dermatologia, Rio de Janeiro, 2000;75(4):393-420.

9. Galdyn IA, Chidester J, Martin MC. The reconstructive challenges and approach to patients with excoriation disorder. J Craniofac Surg. 2015;26(3):824-825. doi:10.1097/SCS.0000000000001514.

10. Grossbart, TA., Sherman C. Skin deep: a mind /body program for healthy skin. $2^{\text {th }}$ ed. Santa Fé, New México: Health Press, 1992:1-40. 
11. Erskine, RG. Theories and methods of an integrative transactional analysis. San Francisco: TA Press, 1977:79-95.

12. Cunha MGG., Crivellari,H. Caminhando com a psicoterapia integrativa.Belo Horizonte: Cultura, 1996:19.

13. Fitzpatrick, JE., Aeling, J.L. Segredos em dermatologia. Porto Alegre: Artmed, 2000:277-300.

14. Yalçin M, Tellioğlu E, Yildirim DU, Savrun BM, Özmen M, Aydemir EH. Psychiatric Features in Neurotic Excoriation Patients: The Role of Childhood Trauma. Noro Psikiyatr Ars. 2015;52(4):336341. doi:10.5152/npa.2015.9902.

15. Prazeres AM, Souza WF, Fontenelle LF. Terapias de base cognitivo-comportamental do transtorno obsessivo-compulsivo: revisão sistemática da última década. Rev Bras Psiquiatr. 2007;29:1-9.

16. Jorge MR. Manual diagnóstico e estatístico de transtornos mentais DSM-IV. Tradução Dayse Batista. 4 ed. Porto Alegre: Artmed; 2002.

17. Schumer MC, Bartley CA, Bloch MH. Revisão sistemática de tratamentos farmacológicos e comportamentais para o distúrbio de palpação de pele. J Clin Psychopharmacol . 2016; 36 (2): 147-152.

18. Vende RR, McGuire JF, BJ pequeno, Storch EA. Uma revisão sistemática e meta-análise de tratamentos psiquiátricos para transtorno de escoriação (palpação de pele). Gen Hosp Psychiatry . 2016; 41: $29-37$.

19. Arnold LM, Auchenbach MB, McElroy SL. Psychogenic excoriation. Clinical features, proposed diagnostic criteria, epidemiology and approaches to treatment. CNS Drugs . 2001;15(5):351-359. doi:10.2165/00023210-200115050-00002.

20. Yurteri N, Sarıgedik E. Skin Picking Successfully Treated With Atomoxetine in Comorbid Skin Picking and Attention-Deficit/Hyperactivity Disorder: A Case Report [published online ahead of print, 2020 Jun 10]. Clin Neuropharmacol. 2020;10.1097/WNF.0000000000000393. doi:10.1097/WNF.0000000000000393.

21. Jenkins Z, Zavier H, Phillipou A, Castle D. Should skin picking disorder be considered a diagnostic category? A systematic review of the evidence. Aust N Z J Psychiatry. 2019;53(9):866-877. doi: $10.1177 / 0004867419834347$. 